\title{
Availability of emergency obstetric and newborn care services at public health facilities of Sindh province in Pakistan
}

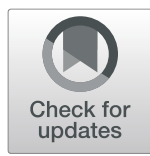

\author{
Ramesh Kumar $^{1 *} \mathbb{D}$, Jamil Ahmed², Fozia Anwar ${ }^{3}$ and Ratana Somrongthong ${ }^{4}$
}

\begin{abstract}
Background: Basic and comprehensive emergency obstetric care services in Pakistan remain a challenge considering continued high burden of maternal and newborn mortality. This study aimed to assess the availability of emergency obstetric and newborn care in Sindh Province of Pakistan.

Methods: This cross-sectional survey was conducted in twelve districts of the Sindh province in Pakistan. The districts were selected based on the maternal neonatal and child health indicators. Data were collected from 63 public-sector health facilities including district, Taluka (subdistrict) headquarters hospitals and rural health centers. Basic and comprehensive emergency obstetric newborn care services were assessed through direct observations and interviews with the heads of the health facilities by using a World Health Organization pretested and validated data collection tool. Participants interviewed in this study included the managers and auxiliary staff and in health facilities.
\end{abstract}

Results: Availability of caesarean section (23, 95\% C.I. 14.0-35.0) and blood transfusion services (57, 95\% Cl. 44.068.0), the two components of comprehensive emergency obstetric and newborn care, was poor in our study. However, assessment of the seven components of basic emergency obstetric and newborn services showed that 92\% of the health facilities (95\% C.I. 88.0-96.0) had parenteral antibiotics, 90\%, (95\% C.I. 80.0-95.0) had oxytocin, 92\% (95\% Cl 88.0-96.0) had manual removal of the placenta service, 87\% (95\%, C.I. 76.0-93.0) of the facilities had staff who could remove retained products of conception, $82 \%$ (95\% C.I. 71.0-89.0) had facilities for normal birth and 80\% (95\% C.I. 69.0-88.0) reported presence of neonatal resuscitation service.

Conclusion: Though the basic obstetric and newborn services were reasonably available, comprehensive obstetric and newborn services were not available as per the World Health Organization's standards in the surveyed public health facilities. Ensuring the availability of caesarean section and blood transfusion services within these facilities may improve population's access to these essential services around birth.

Keywords: Maternal health, Newborn care, Basic and comprehensive emergency obstetric and newborn care

\section{Background}

In 2015, 303,000 maternal deaths were reported globally, of which $99 \%$ occurred in developing countries. About $60 \%$ of this global smaternal mortality burden is shared by only ten countries including India, Nigeria, Afghanistan, Ethiopia, Democratic Republic of the Congo, Tanzania, Kenya, Uganda, Bangladesh, and Pakistan [1]. A lack of access and availability of emergency obstetric care accounts for a large

\footnotetext{
* Correspondence: drramesh1978@gmail.com

${ }^{1}$ Health Services Academy, Islamabad, Pakistan

Full list of author information is available at the end of the article
}

majority of maternal mortality in these countries [2]. Although maternal mortality ratio in Pakistan declined from 521 in 1990 to 178 in 2015, the country still faces a high maternal mortality ratio compared to the regional countries. In bordering India, maternal mortality ratio declined from 556 to 174, in Bangladesh from 569 to 176, in Afghanistan from 1340 to 396, between 1990 and 2015 [3]. The Pakistan Demographic and Health Survey in 2012-2013 reported a maternal mortality ratio of 276 per 100,000 and a neonatal mortality rate of 55 per 1000 [4]. In the province of Sindh, the maternal mortality ratio

(c) The Author(s). 2019 Open Access This article is distributed under the terms of the Creative Commons Attribution 4.0 International License (http://creativecommons.org/licenses/by/4.0/), which permits unrestricted use, distribution, and reproduction in any medium, provided you give appropriate credit to the original author(s) and the source, provide a link to the Creative Commons license, and indicate if changes were made. The Creative Commons Public Domain Dedication waiver (http://creativecommons.org/publicdomain/zero/1.0/) applies to the data made available in this article, unless otherwise stated. 
reported was 314, which was much higher than the national average, indicating wide disparities within country with regard to access to maternal and child healthcare services [5]. The country also faltered in its achievement of Millennium Development Goal of reducing maternal mortality ratio by three quarters, between 1990 and 2015 [6]. Such a failure is reflected by the fact that maternal mortality burden has increased from previous estimates for some parts of Pakistan. For instance, the maternal mortality ratio in Thatta district, in Southern Sindh province, increased more than 50\% from 219 in 2010 to 333 per 100,000 live births in 2013 [7].

Pakistan's maternal and child health burden continues to remain high and coverage of maternal survival interventions is still low despite the investments in recent years, by both public sector and non-governmental organizations. The country's total maternal, newborn and child health expenditure increased by $67 \%$ between 2001 and 2010 [8]. Maternal and newborn deaths in Pakistan could be prevented by improving the access to and availability of basic emergency obstetric and newborn care (BEmONC) and comprehensive emergency obstetric and newborn care (CEmONC) [9].

BEmONC and CEmONC services are offered at various tiers of public healthcare system. BEmONC services including the normal vaginal deliveries, administer oxytocin, newborns resuscitation services are expected to be provided at primary healthcare facilities. CEmONC services were offered for breech presentation, prolonged labor and caesarean section, blood transfusion and care of sick newborns is provided at secondary and tertiary care hospitals. In Sindh, the health system consists of basic health units (BHUs), rural health centers (RHCs), Taluka (subdistrict) headquarter hospitals (THQs), mother and child health $(\mathrm{MCH})$ centers and district headquarters hospitals (DHQs) or civil hospitals. Despite of health facility availability in almost all administrative areas in the province, the availability of and access to quality maternal and newborn care services has been poor $[10,11]$. The present study was sanctioned considering the need for an evaluation of the essential services and resources related to maternal and newborn care provision in the province of Sindh. The study was aimed to encompass the level of infrastructure, equipment and commodities required to deliver emergency obstetric and newborn care services in the province.

\section{Methods}

This cross-sectional study was conducted in twelve of the 29 districts of Sindh Province (Fig. 1). The province had a total population of 47.9 million in 2017 [12]. These districts had poor maternal and child health indicators according to a ranking based on the multiple indicator cluster survey conducted in Sindh in 2014. This
Survey was designed to provide estimates for more than 100 indicators about the women and children's health and social status [13]. The main maternal and child healthcare indicators in the survey were: antenatal and postnatal care, contraception use rate, breastfeeding rate, vaccination coverage, institutional births with skilled providers and proportion of low birth weight babies. We adopted universal sampling technique by interviewing all hospital administrators from $25 \mathrm{RHC}, 28 \mathrm{THQ}$, and 10 DHQ hospitals (Table 1). Questionnaire from World Health Organization (WHO) monitoring emergency obstetric care tool in developing countries was adapted and used after pretesting in adjacent district of Sindh and the availability of EmONC signal functions was assessed by adopting the direct observations WHO recommended check list during this study as described in Table $2[14,15]$. The tool comprised of items on demographic information, availability of equipment and instruments necessary for EmONC. It also contained a checklist to assess EmONC and other maternal child healthcare services like; availability of newborn ward, kangaroo mother care, skilled birth attendance, caesarean section, facility environment and assessment of signal functions of BEmONC and CEmONC. A team of data collectors was trained and data collection quality was ensured by the principal investigator. The data were entered in Microsoft Excel and imported into Statistical Package for Social Sciences version 20 for analysis.

Ethical approval was obtained from the Institutional Review Board of Health Services Academy, Islamabad; administrative permission from health department of Sindh province was also taken for the study.

\section{Results}

\section{EmONC service availability in the health facilities}

From the 63 health facilities surveyed, 25 (40\%) were RHCs; and 28 (44\%) and 10 (16\%) were THQ and DHQ hospitals, respectively. Most of the health facilities $58(92 \%)$ surveyed had parenteral antibiotics available, $57(90 \%)$ of them had uterotonic drugs available for the management of the third stage of labor and postpartum hemorrhage prevention. Fifty two (83\%) facilities had trained staff available to manage eclampsia and preeclampsia by anticonvulsant drug administration and 58(92\%) had trained staff available to perform manual removal of placenta. Most 55(87\%) health facility staff reported that they could perform for dilatation and curettage and vacuum extraction of retained products of placenta and 52(83\%) facilities reported presence of services for assisted vaginal delivery. Newborn care services were available in $51(81 \%)$ of the health facilities. The availability of the BEmONC signal functions was better in DHQ hospitals compared to RHCs and THQs. However, with regard to CEmONC services, only $15(24 \%)$ of the health facilities reported offering 


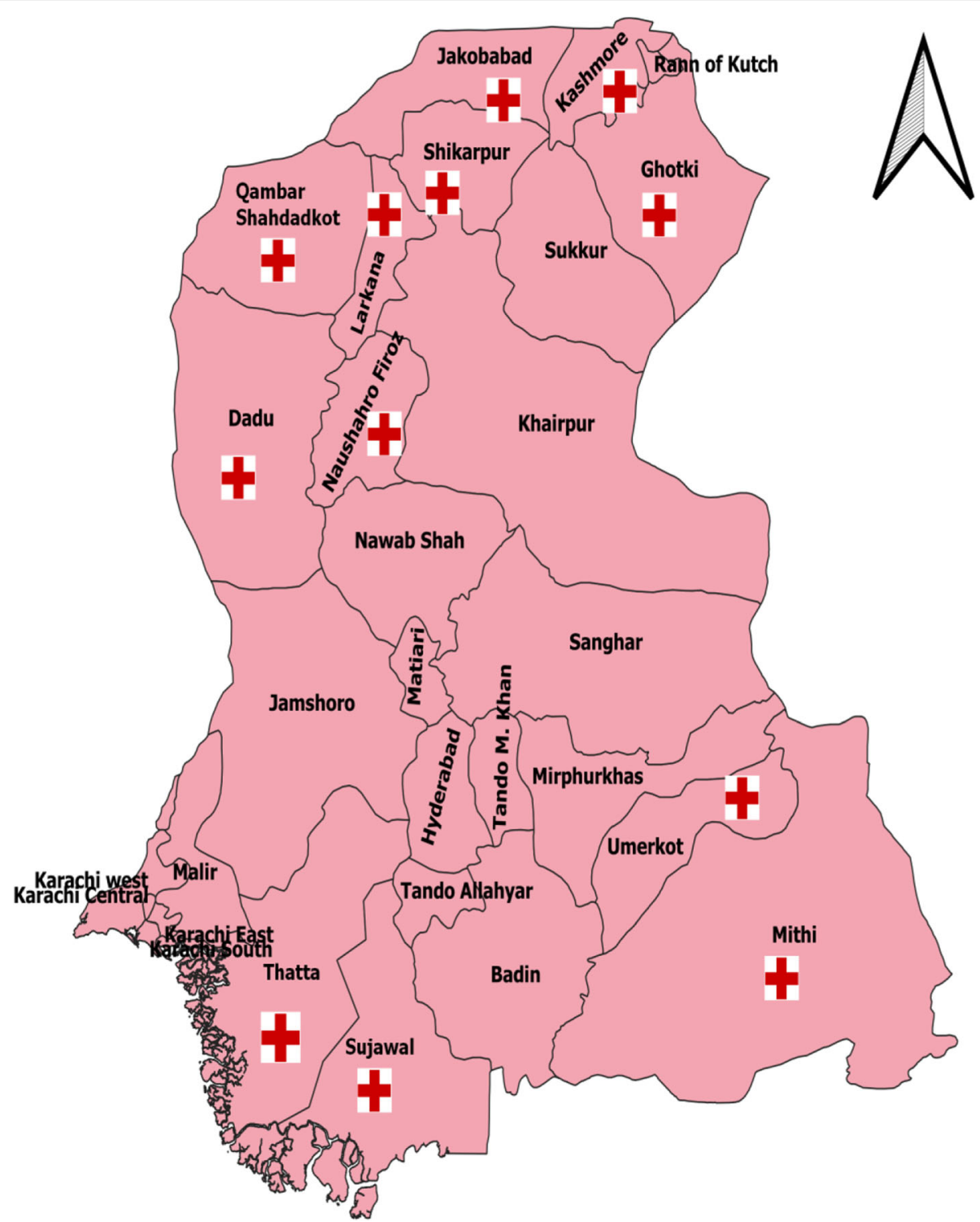

Fig. 1 Geographical distribution of twelve districts surveyed in Sindh province (Developed by using WHO health mapper freely available; https://health-mapper.informer.com/4.3/)

caesarean section services and blood transfusion service was available only in $36(57 \%)$ of the health facilities (Table 2). These services have been verified through observation of the previous hospital record.

\section{Maternal and child healthcare service-related structures and services}

Almost all facilities had antenatal care clinics except three health centers, including RHC New Jatoi, Buxapur and THQ hospital Kashmore. A postnatal ward was available at all DHQ and 18 THQ hospitals. A newborn ward was available in nine DHQ hospitals and about half of THQ hospitals. Labor rooms were available in all surveyed
DHQ and THQ hospitals and RHCs. Equipment for assisted birth (vacuum extraction) was present in all DHQ and 26 THQ hospitals, and in 23 RHCs. Services for the active management of third stage of labor were available in most (84\%) health facilities, and services for the management of pre-eclampsia and eclampsia were available in $81 \%$ of the health facilities and newborn resuscitation service was present in $85 \%$ of the health facilities. Post abortion care services, like manual vacuum aspiration and use of misoprostol were available in $81 \%$ of the health facilities. Protocol for assisted vaginal delivery was present in $84 \%$ facilities. However, a proper referral mechanism did not exist between these facilities (Table 3). 
Table 1 Sociodemographic characteristics of the health facilities assessed in Sindh province $(n=63)$

\begin{tabular}{|c|c|c|c|c|c|c|c|c|c|}
\hline \multirow[t]{2}{*}{ Selected Districts } & \multicolumn{2}{|l|}{ Population } & \multicolumn{2}{|c|}{$\begin{array}{l}\text { Number of district } \\
\text { headquarters hospitals }\end{array}$} & \multicolumn{2}{|c|}{$\begin{array}{l}\text { Number of Taluka } \\
\text { headquarters hospitals }\end{array}$} & \multicolumn{2}{|c|}{$\begin{array}{l}\text { Number of Rural } \\
\text { Health Centers }\end{array}$} & \multirow{2}{*}{$\begin{array}{l}\text { Total } \\
\text { number } \\
\text { of } \\
\text { health } \\
\text { facilities } \\
\text { visited }\end{array}$} \\
\hline & Area $\left(\mathrm{Km}^{2}\right)$ & Catchment population & Total & Selected & $\overline{\text { Total }}$ & Selected & $\overline{\text { Total }}$ & Selected & \\
\hline Dadu & 2551 & $1,089,169$ & 1 & 1 & 4 & 3 & 5 & 1 & 5 \\
\hline Ghotki & 19,808 & $1,649,661$ & 1 & 1 & 5 & 3 & 3 & 1 & 5 \\
\hline Jacobabad & 7705 & 979,817 & 1 & 1 & 3 & 2 & 3 & 3 & 6 \\
\hline Kamber Shahdadkot & 2027 & $1,612,373$ & 1 & 1 & 7 & 4 & 4 & 2 & 7 \\
\hline Kashmore & 2771 & $1,006,297$ & 1 & - & 3 & 1 & 4 & 2 & 3 \\
\hline Larkana & 2577 & $1,231,481$ & 1 & - & 4 & 3 & 5 & 2 & 5 \\
\hline Mithi/ Tharparkar & 5599 & $1,341,042$ & 1 & 1 & 6 & 2 & 2 & 1 & 4 \\
\hline Nausheroferoz & 6506 & $1,647,239$ & 1 & 1 & 5 & 2 & 12 & 2 & 5 \\
\hline Shikarpur & 1906 & $1,524,391$ & 1 & 1 & 4 & 2 & 9 & 4 & 7 \\
\hline Sujawal & 8699 & 781,967 & 1 & 1 & 4 & 2 & 2 & 2 & 5 \\
\hline Thatta & 8034 & $1,550,266$ & 1 & 1 & 3 & 1 & 6 & 4 & 6 \\
\hline UmerKot & 5503 & $1,073,146$ & 1 & 1 & 5 & 3 & 6 & 1 & 5 \\
\hline Total & & & 12 & 10 & 53 & 28 & 61 & 25 & 63 \\
\hline
\end{tabular}

\section{Assessment of guidelines and policies for maternal and child healthcare services}

Guidelines and polices related to maternal and child healthcare provision, case management and quality control mechanism were available in most of the surveyed health facilities; however, these guidelines were more likely to be available within DHQ hospitals compared to lower level health facilities. Less than half of the healthcare staff including doctors and paramedics had received any refresher training on EmONC service provision in the past 6 months. Most health facilities responded that they were gathering and communicating health data regularly (Table 4).

\section{Discussion}

In the present study, availability of BEmONC and CEmNOC signal functions was assessed at the three levels of health care system in twelve districts of Sindh province where the status of maternal and child health, and other social indicators has been historically low. Even though most of the health facilities we surveyed reported high availability of the BEmONC services, the availability of CEmONC sginal functions of cesarean section and blood transfusion was substandard. Almost half of these health facilities lacked necessary guidelines and policies to manage maternal and child health related cases and about half of their staff lacked a recent training on maternal and child health related topic. Our findings are consistent with a previous multi-country survey which reported high availability of BEmONC services [16]. Studies have consistently showed that a low EmONC coverage in developing countries is linked with poor maternal and child health indicators [17-19]. The reason

Table 2 Reported emergency obstetric and neonatal care signal functions in the health facilities of Sindh Province

\begin{tabular}{|c|c|c|c|c|c|c|c|c|}
\hline \multirow[t]{2}{*}{ BEmONC Signal functions } & \multicolumn{2}{|c|}{ All health facilities $(n=63)$} & \multicolumn{2}{|c|}{$\mathrm{RHCs}(n=25)$} & \multicolumn{2}{|c|}{ THQs $(n=28)$} & \multicolumn{2}{|c|}{ DHQs $(n=10)$} \\
\hline & $\overline{n(\%)}$ & $95 \% \mathrm{Cl}$ & $\overline{n(\%)}$ & $95 \% \mathrm{Cl}$ & $\overline{n(\%)}$ & $95 \% \mathrm{Cl}$ & $\overline{n(\%)}$ & $95 \% \mathrm{Cl}$ \\
\hline 1. Parenteral antibiotics & $58(92)$ & $92(88.0-96.0)$ & 23(92) & $92(75.0-97.0)$ & 25(89) & 89(72.0-96.0) & 10(100) & 100(72.0-100.0) \\
\hline 2. Parenteral Oxytocin & $57(90)$ & $90(80.0-95.0)$ & $22(88)$ & 88(70.0-95.0) & 25(89) & 89(72.0-96.0) & 10(100) & 100(72.0-100.0) \\
\hline 3. Parenteral anticonvulsants & $54(83)$ & $83(75.0-92.0)$ & $21(84)$ & 84(65.0-93.0) & 25(89) & 89(72.0-96.0) & $8(80)$ & $80(49.0-94.0)$ \\
\hline 4. Manual removal of placenta & $58(92)$ & $92(88.0-96.0)$ & 23(92) & $92(75.0-97.0)$ & 26(93) & $92(77.0-98.0)$ & $9(90)$ & $90(59.0-98.0)$ \\
\hline 5. Removal of retained products & $55(87)$ & $87(76.0-93.0)$ & $20(80)$ & $80(60.0-91.0)$ & 25(89) & 89(72.0-96.0) & 10(100) & 100(72.0-100.0) \\
\hline 6. Assisted vaginal delivery & $52(83)$ & $82(71.0-89.0)$ & 19(76) & $76(56.0-88.0)$ & 23(82) & $82(64.0-92.0)$ & $10(100)$ & $100(72.0-100.0)$ \\
\hline 7. Neonatal resuscitation & $51(81)$ & $80(69.0-88.0)$ & $20(80)$ & $80(60.0-91.0)$ & $22(79)$ & $78(60.0-89.0)$ & $9(90)$ & $90(59.0-98.0)$ \\
\hline \multicolumn{9}{|l|}{ CEmONC Services } \\
\hline 1. Caesarean birth & $15(24)$ & $23(14.0-35.0)$ & $0(0)$ & $0(0.0-13.0)$ & $9(54)$ & $32(17.0-50.0)$ & $6(60)$ & $60(31.0-83.0)$ \\
\hline 2. Blood Transfusion & $36(57)$ & $57(44.0-68.0)$ & $11(44)$ & $44(26.0-62.0)$ & $16(57)$ & $57(39.0-73.0)$ & $9(90)$ & $90(59.0-98.0)$ \\
\hline
\end{tabular}


Table 3 Reported availability of maternal and child health related services in surveyed health facilities of Sindh Province

\begin{tabular}{|c|c|c|c|c|c|c|c|c|}
\hline \multirow[t]{2}{*}{ Indicators } & \multicolumn{2}{|c|}{ All health facilities $(n=63)$} & \multicolumn{2}{|c|}{$\mathrm{RHCs}(n=25)$} & \multicolumn{2}{|c|}{ THQs $(n=28)$} & \multicolumn{2}{|c|}{ DHQs $(n=10)$} \\
\hline & $n$ & Percent $(95 \% \mathrm{Cl})$ & $n$ & Percent $(95 \% \mathrm{Cl})$ & $n$ & Percent $(95 \% \mathrm{Cl})$ & $n$ & Percent $(95 \% \mathrm{Cl}$ \\
\hline Adequate number of beds & 60 & $95(86.0-98.0)$ & 24 & $96(80.0-99.0)$ & 26 & $92(77.0-98.0)$ & 10 & 100(72.0-100.0) \\
\hline Newborn ward & 37 & $57(46.0-70.0)$ & 13 & $52(33.0-69.0)$ & 15 & $53(35.0-70.0)$ & 9 & $90(59.0-98.0)$ \\
\hline Kangaroo mother care area /room & 29 & $45(34.0-58.0)$ & 11 & $44(26.0-62.0)$ & 12 & $42(26.0-60.0)$ & 6 & $60(31.0-83.0)$ \\
\hline Postnatal ward & 4 & $71(60.0-82.0)$ & 18 & $72(52.0-85.0)$ & 18 & $64(45.0-79.0)$ & 10 & 100(72.0-100.0) \\
\hline Labor room & 63 & $\begin{array}{l}100 \\
(94.0-100.0)\end{array}$ & 25 & 100(86.0-100.0) & 28 & $100(87.0-100.0)$ & 10 & $86(72.0-90.0)$ \\
\hline Assisted birth (vacuum extraction) & 59 & 93(84.0-97.0) & 23 & $92(75.0-97.0)$ & 26 & 89(77.0-98.0) & 10 & 100(72.0-100.0) \\
\hline $\begin{array}{l}\text { Skilled birth attendants (nurse, midwife, Lady health } \\
\text { visitor and/or a medical doctor) }\end{array}$ & 61 & 95(89.0-99.0) & 24 & $96(80.0-99.0)$ & 27 & $96(82.0-99.0)$ & 10 & 100(72.0-100.0) \\
\hline $\begin{array}{l}\text { Stock out of EmONC specific medicines is available as } \\
\text { per Government supply }\end{array}$ & 47 & $\begin{array}{l}73 \\
(62.0-83.0)\end{array}$ & 17 & $68(48.0-82.0)$ & 21 & $75(56.0-87.0)$ & 9 & $90(59.0-98.0)$ \\
\hline $\begin{array}{l}\text { Facilities ready to provide EmONC services as per } \\
\text { WHO criteria }\end{array}$ & 46 & $71(60.0-82.0)$ & 16 & $64(44.0-79.0)$ & 22 & $80(60.0-89.0)$ & 8 & $80(49.0-94.0)$ \\
\hline Facilities with free caesarean-section & 25 & $39(28.0-52.0)$ & 16 & $64(44.0-79.0)$ & 22 & $78(60.0-89.0)$ & 8 & $80(49.0-94.0)$ \\
\hline
\end{tabular}

for this is that very few health facilities provide accessible caesarean section and blood transfusion services in many developing countries [15]. Our results are also consistent with other similar studies which show a reasonably acceptable availability of basic services; yet more advanced maternal and child health services have been lacking; thereby limiting communities' access to these services and resulting in poor outcomes around birth [20-22]. Most of the maternal and newborn deaths in Pakistan occur at birth and improving access to EmONC services can tremendously improve birth outcomes [9].

Availability of CEmONC signal functions in secondary and tertiary level health facilities is necessary to ensure women and children have access to essential emergency care at birth. Not only the THQ hospitals in our study had low availability of caesarean section service; alarmingly, even most of the DHQ hospitals lacked it. Considering that these districts are geographically large, unavailability of an affordable caesarean section service within their main hospitals may result in access related challenges to the communities. These communities may not afford expenses related to caesarean birth in private hospitals and possibly experience hardships while travelling to the districts where such care may be available. This usually leads to families spending out of pocket leading to catastrophic expenditures. Nevertheless, private hospitals in some districts offer an alternative to absent caesarean section service in public sector hospitals [11].

As with caesarean section, blood transfusion availability as part of the national blood transfusion system, even in the hospitals offering CEmONC services, is still a challenge in countries like Pakistan. Previous research has also identified similar challenges to the provision of blood transfusion in other parts of Pakistan [21], as well as in other countries including Malawi and India which also have high maternal and child mortality [22]. Most patients in Pakistan access blood transfusion service

Table 4 Reported availability of guidelines and policies supporting maternal and child health Services in surveyed health facilities of Sindh province

\begin{tabular}{|c|c|c|c|c|c|c|c|c|}
\hline \multirow[t]{2}{*}{ EmONC service monitoring indicators } & \multicolumn{2}{|c|}{ All health facilities $(n=63)$} & \multicolumn{2}{|c|}{ RHCs $(n=25)$} & \multicolumn{2}{|c|}{ THQs $(n=28)$} & \multicolumn{2}{|c|}{ DHQs $(n=10)$} \\
\hline & $n$ & Percent $(95 \% \mathrm{Cl})$ & $n$ & Percent $(95 \% \mathrm{Cl})$ & $n$ & Percent $(95 \% \mathrm{Cl})$ & $n$ & Percent $(95 \% \mathrm{Cl})$ \\
\hline Availability of MNCH policy and guideline documents & 49 & $77(66.0-86.0)$ & 18 & $72(52.0-85.0)$ & 21 & $75(56.0-87.0)$ & 10 & 100(72.0-100.0) \\
\hline $\begin{array}{l}\text { EmONC quality check-up team nominated at the } \\
\text { hospital }\end{array}$ & 44 & $69(57.0-79.0)$ & 18 & $0.72(52.0-85.0)$ & 17 & $60(42.0-76.0)$ & 9 & $90(59.0-98.0)$ \\
\hline Regular data reporting & 63 & 100(94.0-100.0) & 25 & 100(86.0-100.0) & 28 & $100(87.0-100.0)$ & 10 & 100(72.0-100.0) \\
\hline Facilities supervised in last 3 months & 60 & $95(86.0-98.0)$ & 23 & $92(75.0-97.0)$ & 27 & $96(82.0-99.0)$ & 10 & $100(72.0-100.0)$ \\
\hline Any training in EmONC in 6 months & 31 & $49(37.0-61.0)$ & 10 & $40(23.0-59.0)$ & 15 & $53(35.0-70.0)$ & 6 & $60(31.0-83.0)$ \\
\hline $\begin{array}{l}\text { Availability of Soap/running water or alcohol } \\
\text { rub in Labor Room }\end{array}$ & 56 & 88(78.0-94.0) & 20 & $80(60.0-91.0)$ & 26 & $92(77.0-98.0)$ & 10 & 100(72.0-100.0) \\
\hline $\begin{array}{l}\text { Any referral mechanism for patients during } \\
\text { emergency }\end{array}$ & 56 & 88(78.0-94.0) & 21 & $84(65.0-93.0)$ & 25 & $89(72.0-96.0)$ & 10 & $100(72.0-100.0)$ \\
\hline
\end{tabular}


through private blood transfusion centers by paying out of pocket; these facilities often require patients to arrange a blood donor [23]. Ensuring the availability of blood transfusion facilities could prevent a significant proportion of maternal deaths This is crucial considering that post-partum hemorrhage causes one-fourth maternal mortality burden in the developing countries [24].

Inadequately trained staff with less exposure to refresher trainings was another aspect of poor readiness of the health facilities to provide EmONC services. Availability of skilled and trained human resources for health could also be another challenge for the high maternal mortality ratio in surveyed districts, because employees are often poorly satisfied with their jobs and their work environment is usually suboptimal $[25,26]$. Adequate training of health workers is another area of concern where the trained staff would be able to perform their responsibilities more efficiently which can impact better maternal and newborn health outcomes [27].

\section{Strengths and limitations}

Direct access to the health facilities, use of a standard validated checklist and observations of the key structures and functions in the facilities was a strength of this study. However, since our data collectors relied upon health facility staff and managers for reporting, the actual availability of the services could be lower than is presented. Also, observations of the health facilities were conducted, yet they did not focus on the real time utilization of services by the patients. Although, it was found that the equipment and infrastructure for emergency obstetric care were available in the 12 surveyed districts of Sindh, and some of the health facilities also provided CEmONC services, the quality and patient satisfaction with the range of services was not assessed as it was not one of the aims of the present study.

\section{Conclusion}

Although BEmONC service coverage was high in most of the health facilities in the province; the CEmONC service availability was dismal. Ensuring the availability of cesarean section and blood transfusion facilities in most strategically located secondary and tertiary care health facilities will improve the communities' access to these two essential services and may lead to better maternal and newborn survival. Further research is recommended to directly determine the utilization and quality of EmONC services in the health facilities.

\section{Abbreviations}

BEmONC: Basic Emergency Obstetric and Newborn care; CEmONC: Comprehensive Emergency Obstetric and Newborn care; EmONC: Emergency Obstetric and Newborn Care

\section{Acknowledgements}

We acknowledge the support provided by Rachadapisek Sompote Fund for Postdoctoral Fellowship, Chulalongkorn University Thailand.

\section{Authors' contributions}

RK conceptualized this study, JA drafted the manuscript and helped in the data analysis, FA did data analysis and RS revised manuscript critically and added her intellectual content and finalized the manuscript. All authors have read and approved the final manuscript

Funding

Authors did not receive any funding for this research.

\section{Availability of data and materials}

The datasets used and/or analyzed during the current study are available from the corresponding author on reasonable request.

\section{Ethics approval and consent to participate}

Written consent was obtained from participants of the study and Institutional Review Committee of the Health Services Academy, Islamabad Pakistan has approved the ethical clearance prior to start the data collection (7-82/2017-IERB).

\section{Consent for publication}

Not applicable.

\section{Competing interests}

Author Ramesh Kumar is an Editorial Board Member for this journal. All other authors declare that they have no competing interests.

\section{Author details}

${ }^{1}$ Health Services Academy, Islamabad, Pakistan. ${ }^{2}$ Department of Family and Community Medicine, College of Medicine and Medical Sciences, Arabian Gulf University, Manama, Bahrain. ${ }^{3}$ COMSATS Institute of Information Technology, Islamabad, Pakistan. ${ }^{4}$ College of Public Health Sciences, Chulalongkorn University, Bangkok, Thailand.

Received: 28 January 2019 Accepted: 10 December 2019

Published online: 16 December 2019

\section{References}

1. World Health Organization. Trends in maternal mortality: 1990-2015: estimates from WHO, UNICEF, UNFPA, World Bank Group and the United Nations Population Division: executive summary. 2015.

2. Hammonds R, Ooms G. The emergence of a global right to health normthe unresolved case of universal access to quality emergency obstetric care. BMC Int Health Hum Rights. 2014;14(1):4.

3. Alkema L, Chou D, Hogan D, Zhang S, Moller A-B, Gemmill A, et al. Global, regional, and national levels and trends in maternal mortality between 1990 and 2015, with scenario-based projections to 2030: a systematic analysis by the UN maternal mortality estimation inter-agency group. Lancet. 2016; 387(10017):462-74.

4. National Institute of Population Studies. Pakistan Demographic and Health Survey 2012-13. 2012.

5. Tanzil S, Zahidie A, Ahsan A, Kazi A, Shaikh BT. A case study of outsourced primary healthcare services in Sindh, Pakistan: is this a real reform? BMC Health Serv Res. 2014;14(1):277.

6. Hogan MC, Foreman K, Naghavi M, Ahn SY, Wang M, Makela SM, et al. Maternal mortality for 181 countries, 1980-2008: a systematic analysis of progress towards millennium development goal 5. Lancet. 2010;375(9726):1609-23.

7. Pasha O, Saleem S, Ali S, Goudar SS, Garces A, Esamai F, et al. Maternal and newborn outcomes in Pakistan compared to other low and middle income countries in the global Network's maternal newborn health registry: an active, community-based, pregnancy surveillance mechanism. Reprod Health. 2015:12(2):S15.

8. Malik MA, Nahyoun AS, Rizvi A, Bhatti ZA, Bhutta ZA. Expenditure tracking and review of reproductive maternal, newborn and child health policy in Pakistan. Health Policy Plan. 2017;32(6):781-90

9. Ronsmans C, Graham WJ, group LMSSs. Maternal mortality: who, when, where, and why. Lancet. 2006;368(9542):1189-200. 
10. Shadoul AF, Akhtar F, Bile KM. Maternal, neonatal and child health in Pakistan: towards MDGs by moving from desire to reality. East Mediterr Health J. 2010;16 Suppl:S39-46.

11. Ansari MS, Manzoor R, Siddiqui N, Ahmed AM. Access to comprehensive emergency obstetric and newborn care facilities in three rural districts of Sindh province, Pakistan. Health Res Policy Syst. 2015;13(Suppl 1):55.

12. Pakistan Bureau of Statistics. Population Census. 2017.

13. UNICEF. Multiple Indicator Cluster Survey of Sindh. 2014.

14. World Health Organization, United Nations Population Fund, Mailman School of Public Health. Averting Maternal Death and Disability \& United Nations Children's Fund. Monitoring emergency obstetric care: a handbook. World Health Organization; 2009. https://apps.who.int/iris/handle/1 0665/44121.

15. Roy L, Biswas TK, Chowdhury ME. Emergency obstetric and newborn care signal functions in public and private facilities in Bangladesh. PLoS One. 2017;12(11):e0187238.

16. Ameh C, Msuya S, Hofman J, Raven J, Mathai M, Van Den Broek N. Status of emergency obstetric care in six developing countries five years before the MDG targets for maternal and newborn health. PLoS One. 2012;7(12):e49938.

17. Ali M, Ahmed KM, Kuroiwa C. Emergency obstetric care in Punjab, Pakistan: improvement needed. Eur J Contracept Reprod Health Care. 2008;13(2):201-7.

18. Paxton A, Bailey $P$, Lobis S, Fry D. Global patterns in availability of emergency obstetric care. Int J Gynecol Obstet. 2006;93(3):300-7.

19. Ouedraogo AM, Ouedraogo/Nikiema L, Meda IB, N'Tapi K, Kouanda S. Indicators of availability, use, and quality of emergency obstetric and neonatal care in Togo in 2012. Int J Gynaecol Obstet. 2016;135(Suppl 1):S7-S10.

20. Utz B, Zafar S, Arshad N, Kana T, Gopalakrishnan S, Van Den Broek N. Status of emergency obstetric care in four districts of Punjab, Pakistan-results of a baseline assessment. J Pak Med Assoc. 2015;65(5):480-5.

21. Midhet F, Becker S, Berendes HW. Contextual determinants of maternal mortality in rural Pakistan. Soc Sci Med. 1998;46(12):1587-98.

22. Manu A, Arifeen S, Williams J, Mwasanya E, Zaka N, Plowman BA, et al. Assessment of facility readiness for implementing the WHO/UNICEF standards for improving quality of maternal and newborn care in health facilities - experiences from UNICEF's implementation in three countries of South Asia and sub-Saharan Africa. BMC Health Serv Res. 2018;18(1):531.

23. Ismail S, Siddiqui S, Shafiq F, Ishaq M, Khan S. Blood transfusion in patients having caesarean section: a prospective multicentre observational study of practice in three Pakistan hospitals. Int J Obstet Anesth. 2014;23(3):253-9.

24. WHO, UNFPA, \& UNICEF. Pregnancy, Childbirth, Postpartum and Newborn Care: A Guide for Essential Practice (3rd ed). 2015. Retrieved from: http:// apps.who.int/iris/bitstream/10665/249580/1/9789241549356-eng.pdf?ua=1.

25. Kumar R, Ahmed J, Shaikh BT, Hafeez R, Hafeez A. Job satisfaction among public health professionals working in public sector: a cross sectional study from Pakistan. Hum Resour Health. 2013;11:2.

26. Shah SM, Zaidi S, Ahmed J, Rehman SU. Motivation and retention of physicians in primary healthcare facilities: a qualitative study from Abbottabad, Pakistan. Int J Health Policy Manag. 2016:5(8):467-75.

27. Kumar R, Somrongthong R, Shaikh BT. Effectiveness of intensive healthcare waste management training model among health professionals at teaching hospitals of Pakistan: a quasi-experimental study. BMC Health Serv Res. 2015;15:81.

\section{Publisher's Note}

Springer Nature remains neutral with regard to jurisdictional claims in published maps and institutional affiliations.

Ready to submit your research? Choose BMC and benefit from:

- fast, convenient online submission

- thorough peer review by experienced researchers in your field

- rapid publication on acceptance

- support for research data, including large and complex data types

- gold Open Access which fosters wider collaboration and increased citations

- maximum visibility for your research: over $100 \mathrm{M}$ website views per year

At $\mathrm{BMC}$, research is always in progress.

Learn more biomedcentral.com/submissions 